\title{
PARA UMA ARQUEOLOGIA DA PSICOLOGIA SOCIAL ${ }^{\mathbf{1}}$ AN ARCHEOLOGICAL ANALYSYS OF THE SOCIAL PSYCHOLOGY
}

\author{
Kleber Prado Filho \\ Universidade Federal de Santa Catarina, Florianópolis, Brasil
}

\section{RESUMO}

Este artigo busca, a partir de uma perspectiva metodológica de Michel Foucault, traçar uma história arqueológica da Psicologia Social no Brasil. Deslocando-se de uma análise epistemológica que se pergunta sobre a cientificidade e a validade ou verdade de pressupostos, conceitos e técnicas aplicados no campo, a reflexão aqui empreendida coloca em questão seus movimentos e tendências históricas, os enfrentamentos e rupturas observáveis entre as diversas abordagens ali circulantes, bem como a emergência desta multiplicidade de objetos que se formam e se sucedem neste domínio de conhecimentos e práticas ao longo do século XX e neste início de século XXI.

Palavras-chave: arqueologia; história; psicologia social; Michel Foucault.

\begin{abstract}
This article aims to set an archaeological history of Social Psychology in Brazil based on Michel Foucault's methodological perspective. Shifting from an epistemological analysis that asks itself about the scientificity and the truth or validity of presumptions, concepts and techniques applied in field, the argument presented here questions its movements and historical trends, the confrontments and ruptures observable among the many approaches orbiting there, as well as the emergency of multiple objects which form and succeed in this domain of knowledge and procedures throughout the 20th century and in the first years of 21 st century.
\end{abstract}

Keywords: archaeology; history; social psychology; Michel Foucault.

\section{Considerações metodológicas}

Esta reflexão, marcando diferença em relação a uma reflexão epistemológica, busca fazer uma análise arqueológica da Psicologia Social no Brasil aplicando o método de análise de discurso de Michel Foucault - portanto de uma perspectiva exterior aos conteúdos e "verdades" circulantes neste campo - traçando uma história da formação desta disciplina entre nós, ao longo do século XX e nessa passagem ao XXI. Para tanto, faz-se necessário, de partida, proceder a uma distinção de caráter metodológico, entre uma análise epistemológica e a análise arqueológica pretendida.

Uma análise epistemológica centra-se na problemática das condições para a existência de verdades em um campo de conhecimento. Ela deve necessariamente entrar na questão da cientificidade de uma disciplina: questionar a validade das afirmações, a solidez dos pressupostos e argumentos, a visibilidade e acessibilidade dos objetos, a coerência dos métodos, a definição de um campo, a existência ou não de um paradigma, além de verificar a consistência da relação teoria $\mathrm{x}$ prática neste campo. A rigor, ela deve se pronunciar quanto ao atendimento ou não das condições para que determi- nado domínio de conhecimento possa ser considerado científico, e deve ainda, no caso de concorrerem várias tendências num mesmo campo, posicionar-se quanto às diferenças de cientificidade entre elas: qual a mais "científica", qual a mais "verdadeira", qual a mais "confiável" entre elas?

Uma análise epistemológica pode aplicar ou não um olhar histórico à formação de um campo de conhecimento: existem análises epistemológicas mais "fundamentalistas" - de caráter mais positivista - especificamente centradas nos problemas da validade, da objetividade, quando não, nas possibilidades de quantificação e previsão de eventos, assim como existem sem necessariamente se excluírem - análises que levam em conta, em diferentes intensidades de importância, a historicidade da formação de um campo, quando não, a própria historicidade das verdades produzidas neste domínio. Considerando a grande diversidade de perspectivas, pode-se afirmar que é a aplicação de um olhar histórico que marca as análises epistemológicas levadas a efeito no campo da História do Conhecimento, ou das Ideias, porém, não é suficiente tomar o conhecimento em seu movimento histórico: é necessário, ainda, desviar-se da verificação da existência de verdades - é 
preciso deslocar-se da problemática da ciência, diria Michel Foucault.

Uma análise arqueológica é necessariamente histórica e apresenta singularidades em relação às análises epistemológicas tradicionais. Ela procede uma análise dos discursos que não entra na questão da cientificidade, da validade e da existência de verdade em determinado campo - porque esta é a principal condição para que se possa afirmar este campo como científico. Antes de se perguntar sobre a constituição de um domínio de conhecimento científico ela volta-se para as condições de possibilidades presentes na formação de um campo de saber - por isto: arqueologia do saber - porque, por conceito, "conhecimento" é sinônimo de ciência - é sempre conhecimento científico - e "saber" não necessariamente tem este status. Coexistem em nossa cultura muitos regimes discursivos: circulam entre nós textos literários, jornalísticos, filosóficos, de Internet - toda uma diversidade de saberes concorrentes - por que apenas os textos científicos são considerados válidos? Por que o discurso científico tem status diferenciado em relação a todos os outros textos circulantes em nossa cultura? Por que tem compromisso com a produção e expressão de verdades? Não exatamente isto é muito mais questão de valor do que de existência de "verdade" - diria Nietzsche - e este é um problema muito mais histórico-político da nossa cultura Ocidental moderna, do que propriamente de comprovação e validação de verdades científicas!

Uma análise arqueológica dá um tratamento político aos discursos, justamente porque não desliga verdade e poder - ao contrário - toma o saber no elemento do poder, deslocando-se em relação à análise epistemológica procedendo a uma análise externa aos discursos. Corta e atravessa camadas discursivas de um campo - porque os discursos se depositam historicamente em camadas - buscando conhecer as condições históricas de possibilidade para a formação de um discurso: em que outros discursos ele se apoia, quais são suas sustentações, seus domínios, suas fronteiras, que objetos emergem neste domínio, como eles concorrem entre si, que acontecimentos, ligações e articulações marcam este campo. E como os discursos são políticos - eles se enfrentam em um campo político - importa, então, conhecer suas lutas: saber que posições estão presentes, como elas se enfrentam, como elas se superam, quais são vitoriosas - em que momento - quais são vencidas, ultrapassadas, e como elas muitas vezes retornam em outra roupagem. Em vez de se perguntar sobre as condições para a existência de verdades num campo discursivo, um estudo arqueológico ocupa-se centralmente da formação histórica e da disciplinarização de um campo de saber - importa mais à análise arqueológica o caráter disciplinar da formação de um campo de saberes e práticas, do que a cientificidade de um domínio de conhecimento.

Marcadas as distâncias em relação a uma análise epistemológica, importa colocar as questões que orientam a reflexão arqueológica aqui proposta: como se forma e se disciplina este campo de saberes e práticas caracterizado como "Psicologia Social" no Brasil? Quais são suas condições históricas e concretas de possibilidade? Que acontecimentos marcam sua formação? Que matrizes teóricas concorrem neste domínio? Que objetos emergem aí? Quando? Como se mesclam, se articulam e se sucedem? Quais são os movimentos deste campo? Quais são suas fronteiras, extensão, perspectivas, tendências e enfrentamentos?

\section{Condições de possibilidade para uma Psicologia Social brasileira}

Traçar a história da Psicologia Social no Brasil implica, de certa forma, percorrer a história da Psicologia Social mais ampla na qual ela se insere, assim, quando ao longo do texto não houver marcação específica é porque refere-se à história mais geral da Psicologia Social, havendo sinalizações para as particularidades do contexto brasileiro quando for o caso.

Evitando levantar polêmicas, podemos partir de um acontecimento conhecido e mais ou menos consensual que não deve ser tomado como "origem" da Psicologia Social, mas aponta para o seu nascimento, o momento no qual ela se destaca do contexto mais amplo das ciências psicológicas para ganhar visibilidade como "área específica" ou "especialidade", com suas particularidades de noções, objetos e métodos: a difusão dos trabalhos de Kurt Lewin nos anos 30/40 do século passado ${ }^{2}$, desenhando um domínio teórico-prático de relações. Nasce, portanto, vinculada a uma matriz funcionalista, debitária da "física social" comtiana, de caráter positivista, como "teoria de campo" aplicada ao movimento dos grupos - a "dinâmica de grupo" - fundando uma vertente da Psicologia Social: a psicossociologia dos grupos, que virá alcançar grande desenvolvimento desde então em organizações diversas, chegando até nós contemporaneamente.

As condições de possibilidade para a Psicologia Social são os domínios mais amplos das Ciências Humanas, particularmente a Psicologia e a Sociologia, não distanciadas da Antropologia e da História - e ela vem marcada pelas contradições destas disciplinas: as dúvidas quanto à cientificidade, os problemas quanto à objetividade, a diversidade de objetos, a falta de unidade no campo, inexistência de paradigma definido, além da necessidade de certa "flexibilização" de condições para ser considerada científica. 
Ela vem também, assim como elas, atravessada por certa polarização política do tipo "direita" x "esquerda" - um tanto ultrapassada hoje em dia - entre pensamento/prática funcionalistas $\mathrm{x}$ práxis materialista-histórico-dialética, que parte estas disciplinas ao meio, politiza o campo, dificulta diálogos e impossibilita relações, criando grandes fossos e disputas teórico-práticos no domínio das Ciências do Homem. São conhecidos os jogos de oposição existentes entre o funcionalismo psicológico acrítico e apolítico x posições mais histórico-críticas no campo da Psicologia. Nos domínios da Sociologia defrontaram-se ao longo de todo o Século XX uma sociologia crítica, engajada - de esquerda - de orientação materialista-histórica, contra as sociologias funcionalistas, "conservadoras", de Weber e Durkheim. A Antropologia e a História também encontram-se enredadas nos mesmos jogos discursivos: a primeira polarizada entre antropologia estrutural-funcionalista, com seus tradicionais objetos e métodos $\mathrm{x}$ antropologia crítica e a outra - a História - cindida entre uma perspectiva continuista, linear, de análise dos fluxos do progresso x história das rupturas, das lutas, conflitos e contradições.

A Psicologia Social emerge como disciplina de fronteira - o que implica um território móvel, não muito demarcado, não exatamente próprio, uma vez que ocupa "terras alheias" e avança sobre territórios vizinhos - colocado nos limites entre a Sociologia e a Psicologia, inserido no campo maior das Ciências Humanas, cujos domínios não se definem conforme critérios de dimensão - do tipo "macro" x "micro" mas por especificidade de objeto.

\section{Formação histórica do campo}

As trajetórias históricas da Psicologia Social no Brasil podem ser traçadas a partir de uma análise da emergência dos seus objetos de estudo - cartografia das suas problematizações - verificando-se ao longo do Século XX grande movimentação e sucessão de figuras no campo, caracterizando uma verdadeira "dança de objetos" em seus domínios.

Dos anos 1940 a 1960, até meados de 1970 quando predominou no campo uma perspectiva funcionalista - os objetos tradicionais eram as atitudes, opiniões e preconceitos, o jogo dos papéis, da percepção pessoal x percepção social, a questão da "influência social", do status, do prestígio, da imagem social. Tal dinâmica de objetos torna visível a influência das várias vertentes do funcionalismo no campo da Psicologia, nas suas faces behaviorista, cognitivista, sistêmica e suas derivações mais atuais. Ela mostra também a predominância da noção de harmonia social - herança das sociologias funcionalistas de Weber e Durkheim - nos domínios da Psicologia Social.

Durante os anos 1960 e 1970 afirma-se no campo a perspectiva da análise institucional, proposta como instrumento de conhecimento e intervenção em grupos, organizações e estruturas diversas a partir de uma análise de seus signos, elementos da sua cultura e suas relações de poder, portanto, tomando as instituições como seus objetos. De proveniência europeia, mantendo fortes ligações com a psicanálise e com o pensamento estruturalista, tem no Brasil penetração e alcance limitados, restringindo-se a alguns centros como Rio de Janeiro e Porto Alegre.

A partir de meados dos anos 1970 deslocam-se os olhares do campo para as problemáticas da identidade $\mathrm{e}$ das representações sociais, inicialmente de perspectivas funcionalistas e posteriormente a partir de posições mais histórico-críticas. A questão da identidade ocupou durante os anos 1980 o lugar de "objeto por excelência" da Psicologia Social, do mesmo modo que a teoria das representações sociais assumiu o status de "abordagem por excelência" no campo em questão - há nessa época uma explosão de estudos acadêmicos voltados ao problema da(s) identidade(s) e/ou aplicando a abordagem das representações sociais. No entanto, na década de 1990 declinam essas duas problematizações, o que significa que elas são deslocadas dos centrais lugares que ocupavam na década anterior.

A questão da identidade emerge num universo de preocupações funcionalistas - quando não "desenvolvimentistas" - relativas às interferências de aspectos sociais, culturais e educacionais, além de normas e regras, na formação da identidade social e pessoal de um indivíduo. Ao longo dos anos 1980 a problematização da identidade vai se politizando de tal forma que vão sendo desmascaradas as práticas de poder envolvidas nos jogos de identidade tão presentes em nossa cultura, o que abre possibilidades para a instrumentalização de práticas concretas de resistência a tais práticas identitárias. Mas o desmascaramento dos jogos de identidade é também o desencantamento com a própria questão da identidade, não separadamente em termos teóricos, acadêmicos, mas também, práticos. No final da década de 1980 a crítica da questão da identidade bem como a recusa concreta das formas de identidade e de jogos de identificação tornam evidentes as armadilhas de uma certa política moderna das identidades, além de mostrar o caráter fascista de tais práticas, e das próprias lutas identitárias.

A questão das representações sociais, por seu lado, ocupa curioso lugar no campo da Psicologia Social. Este conjunto teórico-prático - ao mesmo tempo objeto, método e teoria - apresenta-se nos anos 1980 como possibilidade de unificação paradigmática neste domínio 
do conhecimento psicológico, garantindo cientificidade, buscando criar uma linguagem comum e produzir uma "pacificação" do campo à direita e à esquerda, projeto que no entanto não chega a se realizar, perdendo força ao longo dos anos 1990. Vale lembrar que a noção de representação social provém da sociologia funcionalista de Durkheim - é debitaria da sua noção de "representação coletiva" - havendo sido trazida para o campo da Psicologia Social nos anos 1960/70 por Moscovici, ganhando expressão ao longo dos anos 1980, havendo sido amplamente aplicada tanto em estudos de orientação funcionalista quanto materialista histórica.

\section{Uma ruptura: a politização do campo}

Ainda ao longo dos anos 1980 - à medida que o campo vai se politizando - as "relações" começam a entrar em cena como objetos: problematiza-se a historicidade dos fenômenos, seu movimento, os conflitos, a dialética. $\mathrm{O}$ foco na comunidade emerge neste momento com tal intensidade que chega a distorcer o campo, gerando confusão entre Psicologia Comunitária e Psicologia Social. Parece instalar-se agora - sem exclusão de outras perspectivas concorrentes - certo paradigma histórico-crítico, que não se restringe à perspectiva materialista-histórico-dialética, mas abre-se a outras modalidades de concepções históricas e políticas, ligadas a outras tradições críticas.

Passam a predominar a partir de então concepções mais sociais de sujeito, colocando em questão a historicidade da sua constituição: opera-se no campo uma desnaturalização e dessubstancialização da subjetividade. As problemáticas da identidade e das relações entre consciência individual $\mathrm{x}$ consciência coletiva são colocadas em outras bases, tendo em conta a produção ideológica capitalista de representações, significados e sentidos. Afirma-se agora a matriz materialista-histórica no campo, com foco na noção de conflito social, e o acontecimento discursivo que se encontra imediatamente ligado a estas rupturas e transformações - pelo menos no Brasil - diz respeito à tardia entrada em cena da psicologia sócio-histórico-cultural ${ }^{4}$. Pode-se dizer que Vigostsky inaugura uma posição autenticamente social, histórica e crítica nos campos da Psicologia Social e da própria Psicologia brasileiras, o que justifica a importância do seu surgimento. Destaca-se neste momento, ligado a esta matriz teórica, o trabalho do grupo de pesquisas vinculado ao Programa de Pós-graduação da PUC/SP em torno da construção de uma Psicologia Social crítica brasileira comprometida com questões latino-americanas.

Um acontecimento imediatamente ligado a essa politização do campo da Psicologia Social no Brasil diz respeito à fundação da ABRAPSO em 1980, associação que desde então tem mantido certa hegemonia na discussão e condução dos rumos da Psicologia Social entre nós, através da organização de encontros científicos regionais e nacionais onde são promovidos debates acadêmicos e definidas políticas de ação para a área.

\section{Nova ruptura: perspectivas atuais}

Contemporaneamente ${ }^{5}$ - mas já a partir da última década do século XX - multiplicam-se novos objetos e a Psicologia Social abre-se para novas perspectivas, ultrapassando a polarização entre posições funcionalistas $\mathrm{x}$ materialista-histórico-dialética. Na dança dos objetos a questão da identidade cede lugar a uma problematização da "diferença" nos domínios das questões éticas, estéticas, étnicas, de gênero, da sexualidade, conjugalidade, maternidade e paternidade. A exemplo do que acontece no campo da Sociologia, entra em falência o modelo revolucionário marxista clássico de transformação social - centrado na "luta de classes" - tornando possível o foco na capilaridade social, na transversalidade das lutas, nos movimentos de resistência e recusa aos modos capitalísticos de subjetivação, no agenciamento de singularizações.

Num texto intitulado "O sujeito e o poder" Foucault afirma que os alvos das lutas políticas contemporâneas não são mais o "Estado" e/ou o "Capital", mas deve-se resistir capilarmente, cotidianamente, aos modos de subjetivação, individualização e identificação impostos por nossa sociedade, o que implica processos de singularização. E é exatamente o deslocamento da luta política dos alvos do Estado e do Capital que coloca a questão da transversalidade dos enfrentamentos, desviando o olhar da formação das "hegemonias revolucionárias" para a capilaridade das estratégias cotidianas de agenciamento, enfrentamento e resistência.

A subjetividade bem como processos de singularização vem, desde então, impondo-se como objetos por excelência não apenas da Psicologia Social, mas da própria ciência psicológica - uma nova matriz teórica entra em cena: a desconstrução nietzschiana, a partir do desenvolvimento e aplicação dos trabalhos de Foucault, Deleuze, Guattari e Derrida em termos da dissolução e historicização radical da subjetividade por eles proposta.

Para finalizar, retomando a questão metodológica colocada no início, deve-se ressaltar que a análise arqueológica aqui empreendida efetivamente não se pronunciou sobre a cientificidade das abordagens citadas, sobre a validade ou veracidade dos seus pressupostos, conceitos ou práticas, nem se posicionou quanto a qual seria "a melhor Psicologia Social" entre todas, mas buscou, de um ponto exterior aos conteúdos e técnicas aplicados em cada uma delas, cartografar o campo da Psicologia Social: mostrar seus movimentos, suas relações, seus objetos, as diferenças e rupturas entre 
essa diversidade de posições que aí se enfrentam, suas emergências e proveniências históricas, bem como as linhas de força e enunciação atuantes no campo.

\section{Notas}

1 Comunicação apresentada em mesa-redonda no $\mathrm{X}^{\mathrm{o}}$ Encontro Regional Sul da Abrapso em Curitiba, 2004.

2 Este é um marco arbitrário e, apesar de bastante aceito, pode ser colocado em questão e tornar-se objeto de controvérsias: basta lembrar que já nos anos 1920 Vigostsky e seus colaboradores vinham trabalhando uma concepção autenticamente social e histórica de sujeito e da própria ciência psicológica. O problema é que a difusão dos seus estudos no Ocidente foi muito lenta, chegando ao Brasil somente nos anos 1980, o que de qualquer maneira e mesmo tardiamente, não diminui a importância da Psicologia sócio-histórico-cultural no contexto da Psicologia Social brasileira, como veremos mais adiante.

3 No sentido de se sustentarem em "teorias do desenvolvimento" e estarem ligadas à problematização da "formação da personalidade".

4 É uma questão bastante conhecida, mas não custa lembrar que a psicologia de Vigotsky entrou tardiamente no Brasil nos anos 1980 - devido a restrições ideológicas e políticas impostas pela ditadura militar que dominou a sociedade brasileira de meados dos anos 1960 a meados dos anos 1980 .

5 Essas análises relativas a questões mais recentes - a partir dos anos 1980 - apesar de tratarem também da situação mais ampla da Psicologia Social, referem-se mais especificamente ao contexto histórico brasileiro, que evidentemente não se encontra desligado do contexto maior onde se insere.

\section{Referências}

Foucault, M. (1995). O sujeito e o poder. In H. Dreyfus \& P. Rabinow, Michel Foucault: uma trajetória filosófica (pp.231250). Rio de Janeiro: Forense Universitária.

Guattari, F. \& Rolnik, S. (1986). Micropolitica: cartografias do desejo. Petrópolis, RJ: Vozes.

Recebido em: 17/11/2009

Revisão em: 05/01/ 2010

Aceite final em: 04/05/2010

Kleber Prado Filho é Psicólogo pela PUC de Minas Gerais e Doutor em Sociologia pela Universidade de São Paulo. Professor da Graduação e do Programa de Pós-Graduação em Psicologia da Universidade Federal de Santa Catarina. Endereço: Caixa Postal 5068. Florianópolis/SC, Brasil. CEP 88040-970. Email: kprado@brturbo.com.br

\section{Como citar:}

Prado Filho, K. (2011). Para uma arqueologia da psicologia social. Psicologia \& Sociedade, 23(3), 464-468. 